\section{LAW ISSUE POTRET REFORMASI HUKUM DI TANAH AIR}

Mahasiswa dalam lapisan masyarakat berperan sebagai iron stock; agent of change; social control; moral force dan guardian of value. Mahasiswa juga bertindak sebagai pemimpin yang mampu serta terampil, baik sebagai pemimpin masyarakat maupun dalam dunia kerja nantinya; dapat menjadi daya penggerak yang dinamis bagi proses modernisasi dalam kehidupan masyarakat. Selain Mahasiswa juga berada di dalam banyak perubahan yang terjadi di sebuah negara, Mahasiswa sebagai generasi yang sedang dipersiapkan untuk melanjutkan tali estafet para pendahulu alangkah baiknya jika kritis dalam menemukan sebuah kesalahan dan mengkaji masalah tersebut untuk menemukan solusinya atau mengambil sikap atas kejadian yang terjadi.

Departemen Aksi Strategis Himpunan Mahasiswa Fakultas Hukum Universitas Pelita Harapan merangkum seluruh peristiwa yang terjadi dalam kurun waktu dua tahun ini melewati kajian yang telah kami lakukan dan menyatukannya menjadi sebuah buku edisi bernama Law Issue yang akan terbit setiap tahun dari Departemen Aksi Strategis. Dalam Law Issue \#1, tema yang diangkat dalam adalah Potret Reformasi Hukum di Tanah Air. Berisi total 12 kajian yang merupakan hasil pemikiran, penelitian, dan diskusi terkait peristiwa hukum yang terjadi di Tanah Air.

Kami selaku Mahasiswa Hukum, haruslah menyikapi dan menanggulangi beberapa peristiwa secara ideal, menurut hukum dan realita sosialnya. Dalam kurun waktu dua tahun selama kami masingmasing bertugas, banyak hal yang kami dapat melewati isu-isu di dalam masyarakat, maka dari itu kami mau mengabadikan pelajaran-pelajaran yang telah kami dapat dari isu-isu ini kepada generasi selanjutnya untuk mengembangkan kemampuan dalam berpikir kritis serta menuangkan aspirasi dalam bentuk kajian ilmiah.

Dalam buku ini banyaknya tukar pikiran antar Mahasiswa yang telah kami rangkum melewati diskusi-diskusi dan program kerja lainnya yang pernah kami lakukan juga, agar dapat terciptanya suatu solusi penyelesaian yang bukan berasal dari latar belakang sepihak melainkan dari mahasiswa, akademisi, serta Tokoh Nasional yang mampu memberikan tambahan segi berfikir yang konkrit atas isu-isu yang kami kaji. Mengingat pentingnya peran mahasiswa maka perlu adanya suatu pengelolaan yang tepat untuk setiap karya tulis atau kajian yang telah dibuat, sehingga fungsi dari kajian itu terus hidup diantara mahasiswa dan juga solusi serta sikap yang diberikan segera terwujud.
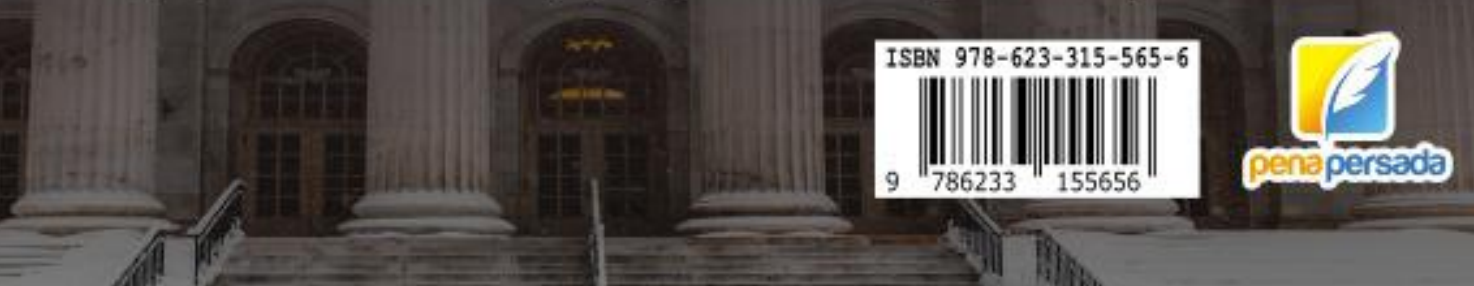

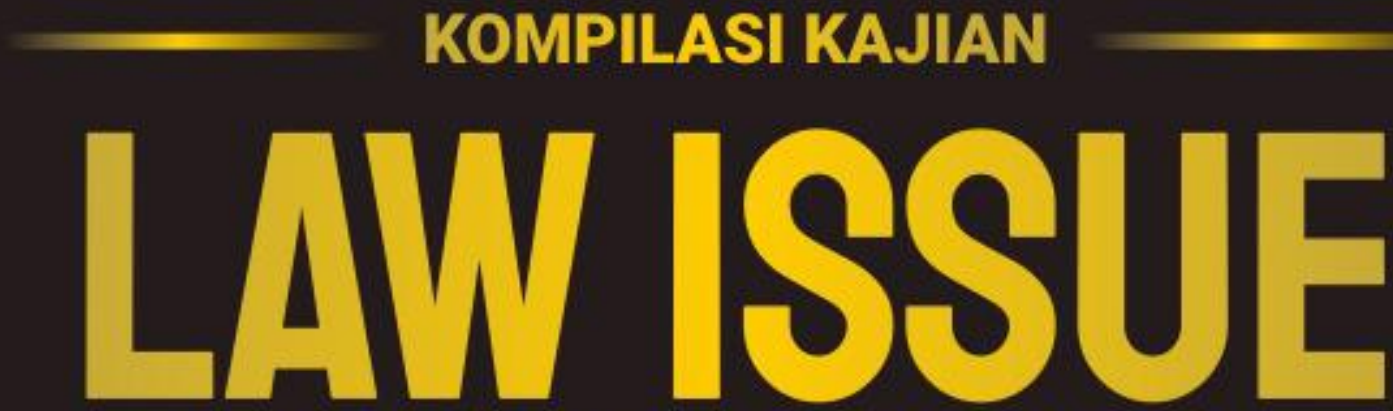

\section{POTRET REFORMASI HUKUM DI TANAH AIR}

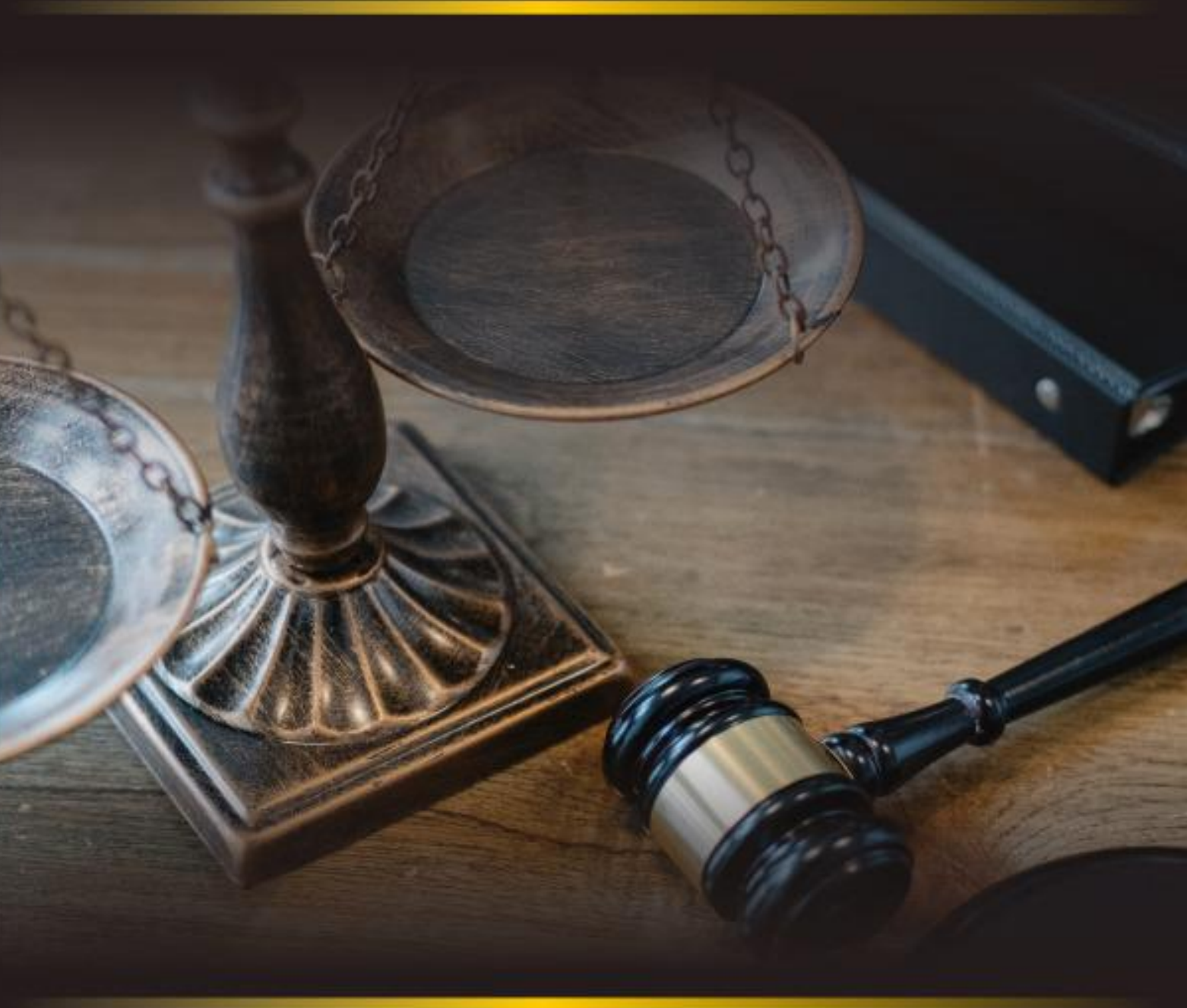

Abraham Ethan | Abraham Misael Halim | Axel Victor | Brandon Hartanto Carlo Axton Lapian | Charren Hendrik | Chelsea Claresta | Dhaffa Achsanul Putri Miqaila Ameena | Rebeka Tiramine 


\title{
KOMPILASI KAJIAN
}

Law Issue: Potret Reformasi Hukum di Tanah Air

\author{
Abraham Ethan \\ Abraham Misael Halim \\ Axel Victor \\ Brandon Hartanto \\ Carlo Axton Lapian \\ Charren Hendrik \\ Chelsea Claresta \\ Dhaffa Achsanul \\ Putri Miqaila Ameena \\ Rebeka Tiramine \\ William Chindrawa
}

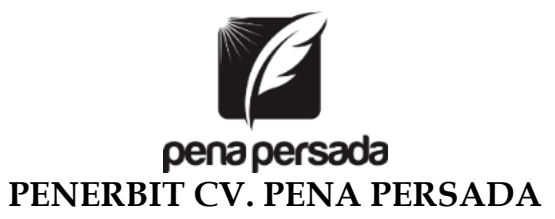




\title{
KOMPILASI KAJIAN \\ Law Issue: Potret Reformasi Hukum di Tanah Air
}

\author{
Penulis: \\ Abraham Ethan, Abraham Misael Halim, Axel Victor, \\ Brandon Hartanto, Carlo Axton Lapian, Charren Hendrik, \\ Chelsea Claresta, Dhaffa Achsanul, Putri Miqaila Ameena, \\ Rebeka Tiramine, William Chindrawa
}

ISBN: 978-623-315-565-6

Design Cover:

Retnani Nur Briliant

Layout:

Nisa Falahia

Penerbit CV. Pena Persada

Redaksi:

Jl. Gerilya No. 292 Purwokerto Selatan, Kab. Banyumas

Jawa Tengah

Email: penerbit.penapersada@gmail.com

Website: penapersada.com Phone: (0281) 7771388

Anggota IKAPI

All right reserved

Cetakan pertama: 2021

Hak Cipta dilindungi oleh undang-undang. Dilarang memperbanyak karya tulis ini dalam bentuk apapun tanpa izin penerbit 


\section{KATA PENGANTAR}

Puji dan Syukur kami panjatkan kepada Tuhan yang Maha Esa atas segala rahmat yang telah diberikan oleh-Nya. Dalam periode Departemen Aksi Strategis HMFH 2019/2020 dan 2020/2021 banyak kajian yang telah dilakukan berdasarkan dengan isu-isu hukum yang terjadi di tanah air sebagai potret reformasi hukum. Maka dari itu judul dari rangkuman kajian strategis adalah "Potret Reformasi Hukum di Tanah Air". Tulisantulisan yang dimuat adalah pengamatan serta analisis berdasarkan peraturan-peraturan hukum yang dianggap penting. Tidak lupa juga penulis mengucapkan terima kasih atas bantuan dari pihakpihak yang telah berkontribusi dengan memberikan sumbangan baik materi-materi maupun pemikiran-pemikirannya. Rangkuman kajian ini penulis buat sebagai salah satu program kerja Departemen Aksi Strategis periode 2019/2020 dan 2020/2021.

Dalam penyusunan rangkuman beberapa kajian ini, tentu penulis mendapati banyak tantangan dan hambatan. Penulis menyadari bahwa rangkuman-rangkuman kajian ini adalah hasil dari kerjasama Departemen Aksi Strategis. Kritik dan pendapat dari pembaca tentu diperlukan penulis untuk memperbaiki rangkuman selanjutnya. Harapan penulis semoga rangkuman kajian ini dapat menambah wawasan dan pengetahuan bagi para pembaca.

Tim Penulis 


\section{DAFTAR ISI}

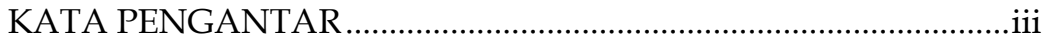

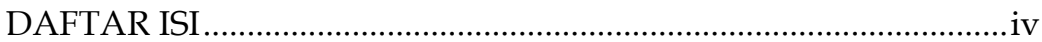

KAJIAN 1 EFEKTIFITAS INSTRUKSI GUBERNUR DKI

JAKARTA NO. 66 TAHUN 2019 TENTANG PENGENDALIAN KUALITAS UDARA DALAM

MENGATASI POLUSI UDARA DI JAKARTA ............... 1

KAJIAN 2 TOLAK UKUR “KEMIRIPAN" DALAM HAK

CIPTA LAGU STUDI KASUS HAK CIPTA LAGU

SUSU MURNI NASIONAL ........................................... 10

KAJIAN 3 PENERAPAN OMNIBUS LAW DI INDONESIA........... 18

KAJIAN 4 KAJIAN PERNYATAAN SIKAP TERHADAP

BEBERAPA PASAL DALAM RANCANGAN

KITAB UNDANG-UNDANG HUKUM PIDANA

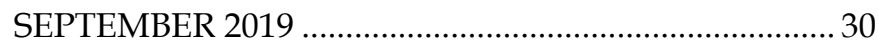

KAJIAN 5 BERPRAKTIK HUKUM TANPA MANUSIA .................. 48

KAJIAN 6 HUKUMAN KEBIRI DITINJAU DARI SUDUT

PANDANG PSIKOLOGI DAN HAM............................ 58

KAJIAN 7 PERAN MAHASISWA DALAM ISU-ISU POLITIK,

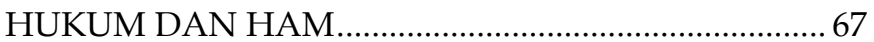

KAJIAN 8 EFEKTIVITAS KEBIJAKAN PEMBELAJARAN

JARAK JAUH DI INDONESIA ........................................ 80

KAJIAN 9 KEBIJAKAN PEMBATASAN SOSIAL BERSKALA

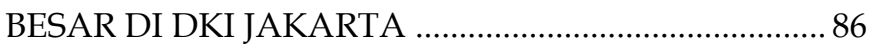

KAJIAN 10 PERLINDUNGAN HUKUM BAGI PEREMPUAN

KORBAN TINDAK KEKERASAN DILIHAT DARI

KESETARAAN GENDER MELALUI MATA

HUKUM INDONESIA

KAJIAN 11 PROBLEMATIKA KONSTITUSIONAL DALAM

UNDANG - UNDANG NOMOR 2 TAHUN 2020 ..... 103

KAJIAN 12 CATATAN AKHIR TAHUN “LAW REWIND

INDONESIA 2020" 
KAJIAN 13 PENOLAKAN VAKSINASI COVID-19 DITINJAU

DARI PERSPEKTIF HUKUM DAN HAK ASASI

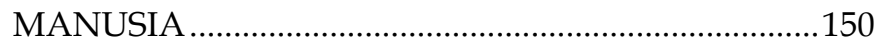

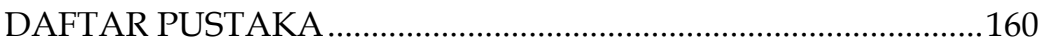




\section{KOMPILASI KAJIAN}

Law Issue: Potret Reformasi Hukum di Tanah Air 


\title{
KAJIAN 1 \\ EFEKTIFITAS INSTRUKSI GUBERNUR DKI \\ JAKARTA NO. 66 TAHUN 2019 TENTANG \\ PENGENDALIAN KUALITAS UDARA DALAM \\ MENGATASI POLUSI UDARA DI JAKARTA
}

--- ** ---

\begin{abstract}
Air pollution in Jakarta, the capital city of Jakarta, has reached critical levels according to AirVisual. Jakarta Regional Governor, Anies Baswedan has issued Governor Instruction No.66 Year 2019 Regarding Air Quality Control to control pollution levels by mitigating it. Such regulations are deemed ineffective as it falls under a certain type of government intervention in which its effectiveness relies on the enforcement of law enforcers.
\end{abstract}

Keyword: Air Pollution, Governor Instruction No.66 Year 2019 Regarding Air Quality Control, Government Intervention

\begin{abstract}
Abstrak
Polusi udara di Ibu Kota DKI Jakarta telah mencapai tingkat berbahaya menurut AirVisual. Untuk menanggulangi hal tersebut, Anies Baswedan sebagai Gubernur DKI Jakarta mengeluarkan Instruksi Gubernur No. 66 Tahun 2019 Tentang Pengendalian Kualitas Udara. Instruksi tersebut tidak efektif karena instruksi tersebut tergolong sebagai intervensi pemerintah dimana efektifitas tergantung pada penegakan hukum oleh aparat penegak hukum.

Kata Kunci: Polusi Udara, Instruksi Gubernur No.66 Tahun 2019 Tentang Pengendalian Kualitas Udara, Intervensi Pemerintah
\end{abstract}

\section{A. Pendahuluan}

Keresahan warga Jakarta terkait polusi udara yang menjadi trending topic ternyata hanya diklasifikasikan sebagai tahapan sedang menurut Kementerian Lingkungan Hidup dan Kehutanan (KLHK). Berbeda dengan data tersebut, Air Visual, 
sebuah software company, per tanggal 11 Agustus 2019 menyatakan bahwa Jakarta pada peringkat ke-3 sebagai kota dengan tingkat polusi udara tertinggi di dunia. Tak hanya itu, Jakarta berhasil mencapai kualitas terburuk di dunia pada tanggal 29 Juli 2019. Terlepas dari kesimpulan yang dikeluarkan oleh KLHK dan AirVisual, polusi udara di Jakarta memang dalam tingkat yang mengkhawatirkan.

\section{Jakarta air quality index (AQI) and PM2.5 air pollution}

2200, Aug 11 (local time)

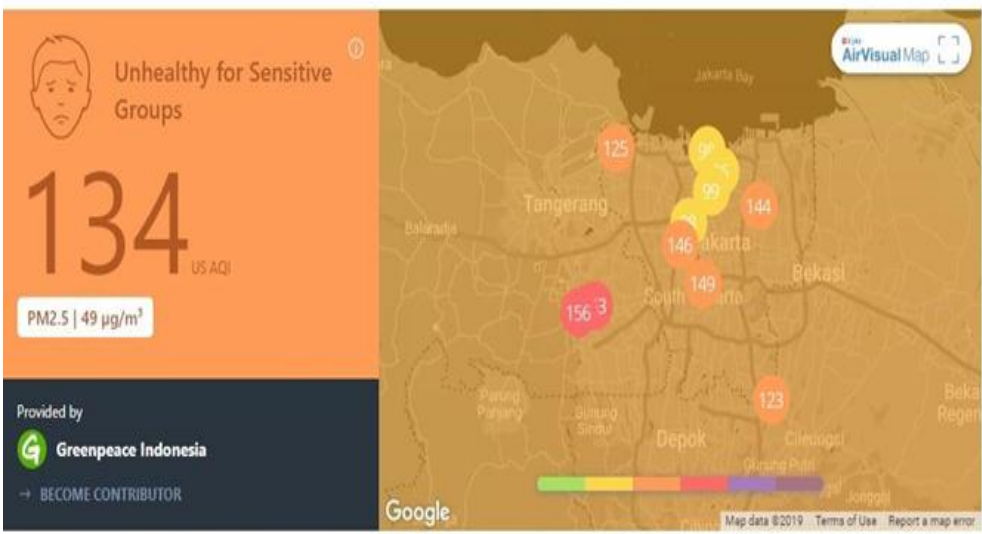

Gambar 1 Data Indeks Kualitas Udara dari AirVisual pada tanggal 11 Agustus 2019 menunjukkan nilai kualitas yang menurut lembaga tersebut dalam level tersebut dapat menimbulkan peningkatan kemungkinan gejala pernapasan pada individu yang sensitif sementara masyar umum mungkin hanya merasa sedikit iritasi. 


\title{
Air quality and pollution city ranking
}

\author{
11 August 2019, 22:47
}

Major city

US AQI

1

E Dubai, United Arab Emirates

157

2

Dhaka, Bangladesh

3

Jakarta, Indonesia

134

4

Tashkent, Uzbekistan

Gambar 2. Data Peringkat Indeks Kualitas Udara Dunia dari AirVisual pada tanggal 11 Agustus 2019 menunjukkan Jakarta berada pada peringkat 3 kualitas udara terburuk di dunia. cсc

Polusi udara merupakan sebuah kondisi masuknya materi atau energi yang dapat menyebabkan kerusakan ekologi akut atau turunnya kualitas hidup. ${ }^{1}$ Sumber polusi udara berasal dari aktivitas manusia yang menghasilkan limbah, emisi transportasi, dan lain-lain yang menyebarkan polutan ke udara. Demi kesehatan masyarakat, polusi udara harus dibatasi. Melihat hal ini, pemerintah melakukan upaya kepada para organisasi maupun perorangan yang menyebabkan polusi udara di Jakarta. Upaya tersebut dikenal juga dengan istilah intervention strategy.

\section{B. Pembahasan}

Intervention strategy merupakan upaya pemerintah dalam mengatasi polusi udara melalui intervensi organisasi atau perorangan yang menjadi penyebab dan penyumbang polusi

${ }^{1}$ Akinwale O. Coker, "Environmental Pollution: Types, Causes, Impacts and Management for The Health and Socio-Economic Well-Being of Nigeria", 2013, hal. 1. 
udara di Jakarta. ${ }^{2}$ Strategi ini juga didampingi oleh constrained discretion, yaitu sebuah diskresi bagi para penegak hukum dalam menentukan berhasil atau tidaknya intervensi pemerintahan tersebut. Strategi ini diklasifikasikan menjadi tujuh macam yaitu, advice and persuasion, rules and deterrence, criteria strategies, responsive regulation, smart regulation, risk-based regulation, meta regulation. Berikut adalah penjelasan dari masing-masing strategi:

\begin{tabular}{|c|c|}
\hline Advice and Persuasion & $\begin{array}{l}\text { Cara penyelesaian masalah melalui } \\
\text { kerja sama dan konsiliasi } \\
\text { ketimbang pemidanaan. }\end{array}$ \\
\hline Rules and Deterrence & $\begin{array}{l}\begin{array}{l}\text { Penegakan } \\
\text { peraturan }\end{array} \text { pelanggaran melalui } \\
\text { (pidana) yang berlaku agar } \\
\text { memiliki efek jera (deterrence). } \\
\text { Adanya efek tersebut dapat } \\
\text { meminimalisir kemungkinan } \\
\text { seseorang untuk melanggar } \\
\text { peraturan. }\end{array}$ \\
\hline Criteria Strategies & $\begin{array}{l}\text { Penegak hukum diberikan } \\
\text { “kriteria-kriteria” } \quad \text { untuk } \\
\text { menyelesaikan suatu masalah. }\end{array}$ \\
\hline Responsive Regulation & $\begin{array}{l}\text { Penyelesaian dengan kerja sama } \\
\text { secara persuasif yang digabungkan } \\
\text { dengan cara koersif. Namun } \\
\text { pendekatan ini tergantung kepada } \\
\text { sikap yang bersangkutan, di mana } \\
\text { pelanggar yang kooperatif akan } \\
\text { baik kerjasamanya dengan } \\
\text { penegak hukum dan yang }\end{array}$ \\
\hline
\end{tabular}

2 Neil Gunningham, "Enforcing Environmental Regulation", Journal of Environmental Law Vol 23 No. 2 Juli 2011, hal. 171 


\begin{tabular}{|c|c|}
\hline & $\begin{array}{l}\text { sebaliknya akan diatur secara } \\
\text { koersif. }\end{array}$ \\
\hline Smart Regulation & $\begin{array}{l}\text { Serupa dengan responsive regulation, } \\
\text { tetapi penegak hukum dalam } \\
\text { strategi ini mempertimbangkan } \\
\text { faktor eksternal, seperti } \\
\text { kesejahteraan rakyat dan ekonomi. }\end{array}$ \\
\hline Risk-based Regulation & $\begin{array}{l}\text { Penegakan hukum tergantung } \\
\text { kepada jenis kasus yang sedang } \\
\text { diselidiki dan implikasi kasus } \\
\text { tersebut. }\end{array}$ \\
\hline Meta Regulation & $\begin{array}{l}\text { Tanggung jawab penyelesaian } \\
\text { masalah diserahkan kepada } \\
\text { masing-masing organisasi atau } \\
\text { perorangan. Strategi ini bertujuan } \\
\text { untuk mengembangkan } \\
\text { kemampuan dan pengetahuan } \\
\text { sebuah organisasi atau perorangan } \\
\text { agar dapat mengatur diri sendiri } \\
\text { dengan tetap diawasi oleh } \\
\text { pemerintah. }\end{array}$ \\
\hline
\end{tabular}

Intervensi pemerintah saat ini terlihat dari Rancangan Undang-Undang nasional dan peraturan daerah. Kajian ini akan memusatkan penelitian dan efektifitas terhadap UndangUndang nasional dalam mengatasi polusi udara di Jakarta yaitu, Undang-Undang No. 32 Tahun 2009 tentang Perlindungan dan Pengelolaan Lingkungan Hidup [UU Lingkungan Hidup], dan khusus untuk DKI Jakarta, Instruksi Gubernur No. 66 Tahun 2019 mengenai Pengendalian Kualitas Udara [Ingub 2019]. Selain itu, kajian ini akan menilai strategi intervensi apa yang sebaiknya digunakan untuk menyelesaikan masalah tersebut. 
Intervensi pemerintah melalui UU Lingkungan Hidup masuk dalam kriteria rules and deterrence dengan penekanan untuk mempidanakan siapapun yang melanggar pasal (rules) agar jera. Deterrence effect diharapkan akan timbul dengan adanya paksaan tersebut dan kemungkinan pelanggaran yang ditangani secara koersif akan berkurang. Hal ini didukung dengan adanya Pasal 84 Ayat (1) UU Lingkungan Hidup yang mencakup criteria strategies. Pasal tersebut memberikan ruang gerak kepada penegak hukum untuk menyelesaikan sengketa di luar ketentuan pidana.

Berdasarkan kajian Ingub 2019 pada responsive regulation yang pelaksanaannya bersifat koersif dan persuasif bergantung pada sikap pelanggar. Ciri khas responsive regulation dalam Ingub 2019 tidak tercerminkan secara eksplisit. Namun, implikasi dari adanya Ingub 2019 mendorong dilakukannya responsive regulation oleh instansi pemerintahan daerah. Tertuang dalam isi Ingub 2019 yang menginstruksikan berbagai badan pemerintahan DKI Jakarta untuk melakukan suatu tindakan dan pelaksanaan instruksi tersebut bergantung kepada kewenangan badan pemerintah. Atas dasar ini, setiap badan pemerintahan akan melihat dan mengkondisikan pelaksanaan tersebut dengan respon warga Jakarta terhadap instruksi tersebut. Sebagai contoh, Bagian 4 (b) Ingub 2019, Kepala Dinas Perhubungan Provinsi DKI Jakarta (Kepala Dishub) diarahkan untuk menyiapkan rekayasa lalu lintas untuk menjaga kelancaran. Berdasarkan instruksi tersebut, dapat diinterpretasikan bahwa Kepala Dishub berperan sebagai pengatur yang akan membuat rencana untuk menjaga kelancaran lalu lintas. Respon dari warga jakarta akan sangat mempengaruhi seberapa berat aturan yang dilaksanakan. Disini akan terlihat perpaduan kooperatif dan negosiasi yang bisa dilihat siapa yang dominan.

Perbedaan intervention strategy yang terlihat dari isi UU Lingkungan Hidup dan Ingub 2019 sendiri merupakan suatu permasalahan. Seharusnya, Ingub 2019 (responsive regulation) yang merupakan produk otonomi daerah dibuat berdasarkan 
UU Lingkungan Hidup (rules and deterrence) yang merupakan tingkat nasional. Hal ini akan memperlihatkan bahwa Ingub 2019 memang ada untuk mendukung pelaksanaan UU Lingkungan Hidup. Responsive regulation tidak mendukung rules and deterrence karena rules and deterrence tidak memberikan ruang untuk kerja sama dan negosiasi seperti responsive regulation. Ketidaksamaan strategi ini menunjukan bahwa Ingub 2019 tidak mendukung apa yang dikehendaki UU Lingkungan Hidup.

Responsive Regulation sendiri juga mempunyai kelemahan yang sangat mendalam dimana suksesnya responsive regulation tergantung pada seberapa aktifnya penegak hukum (constraining discretion). ${ }^{3}$ Sedangkan menurut riset, penegak hukum cenderung menjadi tidak aktif di lapangan. Penegak hukum yang pasif akan mengakibatkan gagalnya mandat yang diberikan kepada badan pelaksana ingub Anies. Sebagai contoh dimana Ingub Anies memerlukan keaktifan penegak hukum terdapat di bagian kesatu pasal 5c, dimana dinas lingkungan hidup DKI Jakarta diminta melakukan penyempurnaan dan sejumlah pengawasan pada pabrik. Hal ini hanya akan berhasil, jika Dinas Lingkungan Hidup DKI Jakarta secara aktif melakukan pengecekan dan penyempurnaan berkala. Jika mereka pasif, maka hasilnya nihil, sama seperti kondisi para penegak hukum yang sekarang pasif sehingga terjadi polusi udara yang tidak terkontrol.

Di mata hukum, Instruksi Gubernur ini juga dapat dikategorikan sebagai beschikking karena bersifat individual dan konkrit. Ingub ini diharapkan hanya akan dikeluarkan sekali untuk mengatasi masalah polusi udara di DKI Jakarta dan karena itu bersifat enmahlig (sekali-selesai). Walaupun itu, Ingub ini tetap memiliki ikatan hukum dan wajib dipatuhi. Pengujian atas Ingub dapat dilakukan melalui peradilan tata usaha negara.

${ }^{3}$ Ibid, hal. 198 


\section{Penutup}

Maka daripada itu, Ingub 2019 dapat dinilai tidak efektif. Hal ini dikarenakan, (1) Ingub 2019 memiliki strategi implementasi yang berbeda dengan UU Lingkungan Hidup sehingga tidak cukup kuat untuk menjadi pelopor terealisasinya UU Lingkungan Hidup sebagaimana mestinya. Selain itu, (2) Strategi responsive regulation yang dimiliki Ingub 2019 tidak akan berjalan dengan baik, karena pelaksanaannya hanyalah dengan adanya keinginan keaktifan para penegak hukum untuk menjalankan UU Lingkungan Hidup dengan benar.

Berdasarkan pemaparan diatas, kami Departemen Aksi Strategis HMFH UPH menyatakan sikap sebagai berikut:

1. Ingub 2019 tidak efektif. Sebaiknya agar pelaksanaan menjadi lebih efektif, Ingub 2019 sebaiknya mengadopsi intervention strategy yang mendukung atau setidaknya mengkomplemen strategi rules and deterrence. Hal ini bertujuan agar mandat dari UU Lingkungan Hidup dapat terlaksana dan tidak terjadi kontradiksi. Seharusnya Ingub Anies memaksa badan-badan penegak hukum untuk bertindak sesuai dengan mandat yang ada di UU Lingkungan Hidup.

2. Ketidakefektifan Ingub 2019 menjadi bukti bahwa pemerintah dapat mengeluarkan produk hukum yang sia-sia dan pemerintah belum berhasil menemukan strategi intervensi yang tepat. Ingub 2019 ini hanyalah akan menjadi peraturan terbengkalai atau hanyalah sia-sia serta pencitraan belaka. Seharusnya pemerintah lebih mementingkan kualitas diatas kuantitas. Lebih baik memakan waktu yang lebih lama untuk sebuah produk hukum yang lebih baik, dibanding tergesa-gesa menciptakan sesuatu yang sia-sia ke depannya, seolah-olah hanyalah menjadi sandiwara dan memberikan harapan palsu terhadap masyarakat.

3. Tindakan seperti ini jangan sampai terulang lagi. Trending topic yang menjadi urgensi warga Jakarta untuk udara yang bersih merupakan bukti kegagalan 
pemerintah dalam menjalankan amanat, tugas dan kewajiban Pemerintah Provinsi DKI Jakarta. Seharusnya pemerintah daerah mempertimbangkan dan melaksanakan dengan baik mandat dari UU Lingkungan Hidup yang menjadi acuan untuk mengatasi polusi udara di Jakarta.

Penyelesaian permasalahan lingkungan hidup selalu dimulai dari kesadaran masyarakat dan pemerintah bahwa lingkungan hidup yang bersih adalah hak seluruh masyarakat. 


\title{
KAJIAN 2 \\ TOLAK UKUR “KEMIRIPAN" DALAM HAK CIPTA \\ LAGU STUDI KASUS HAK CIPTA LAGU SUSU \\ MURNI NASIONAL \\ --. ** ---
}

\begin{abstract}
Up until today, there has been no proper extent of which determines what separates a music to be plagiarized. It is ever increasing that in the music industry that musicians utilized the works of others for their own source of creativity, however, in a legal perspective, what determines a music to be plagiarized is still highly debated.
\end{abstract}

Keywords: Plagiarism, copyright, law, music

\begin{abstract}
Abstrak
Hingga hari ini, belum ada tolak ukur yang dapat memadai untuk membedakan lagu apa yang dapat disebut sebagai plagiat. Dalam industri permusikan, banyak yang memanfaatkan karya lain untuk dapat membantu sumber kreatifitas, namun, dalam sudut pandang hukum, apa yang dapat menentukan lagu sebagai plagiat masih dalam perdebatan.
\end{abstract}

Kata kunci: Plagiarisme, hak cipta, hukum, musik

\section{A. Pendahuluan}

Pada tanggal 30 Juli 2019, Young Lex mempublikasikan lagu karyanya berjudul "Bodo Amat" melalui akun Youtubenya, dengan total penonton lebih dari satu juta pada tanggal 27 Agustus 2019. Didapat dalam beberapa segmen lagunya bahwa lagunya memiliki lirik dan melodi yang sama seperti apa yang sudah diciptakan terlebih dahulu oleh Youtuber Firgiawan Ramaulana melalui akun youtubenya "seterahdeh". Firgiawan pun menyimpulkan bahwa Young Lex mengambil karyanya karena memiliki lirik yang sama. Namun, lagu yang diciptakan oleh Firgiawan adalah lagu dengan lirik yang didasari melodi ciptaan orang lain, yaitu karya Susu Murni Nasional. Dalam lagu Firgiawan, Firgiawan menyanyi sesuai dengan iringan 
lagu susu murni nasional, yang mana ia tambahkan lirik. Namun, dengan adanya klaim bahwa Young Lex mengambil karya Firgiawan, banyak warga dan peneliti yang mengomentari bahwa Young Lex tidak melakukan tindak plagiarisme terhadap Firgiawan, tetapi keduanya melakukan tindak plagiarisme terhadap Susu Murni Nasional, karena sudah memanfaatkan karyanya Susu Murni Nasional demi keuntungan pribadi.

Untuk bisa menilai bahwa apakah benar kedua dari Firgiawan dan Young Lex melakukan tindak plagiarisme, maka harus diperdalam dahulu pengertian terhadap apa itu plagiarisme. Plagiarisme berawal dari kata, plagiarus, bahasa latin ciptaan penyair Roma, Marcus Valerius Martialis yang berarti mencuri karya orang lain. ${ }^{4}$ Seiring jalannya waktu KBBI pun mengeluarkan pernyataan definisi plagiarisme sebagai "penjiplakan atau pengambilan karangan, pendapat, dan sebagainya dari orang lain dan menjadikannya seolah karangan dan pendapat sendiri". Intervensi pemerintah untuk melawan adanya plagiarisme ada dalam upaya perancangan hukum, karena plagiarisme dianggap mencuri hak cipta orang lain. Lantas, itulah mustahil untuk menyatakan bahwa suatu ciptaan adalah hasil plagiarisme, tanpa adanya bahasan dan pengertian lebih lanjut mengenai hak cipta, karena hak cipta lah yang melindungi suatu karya dari tindak plagiarisme. Kasus tersebut akan menjadi pokok pembahasan materi.

\section{B. Pembahasan}

\section{Hak Cipta lagu Susu Murni Nasional}

Hak cipta di Indonesia sudah memiliki kekuatan yuridis yang ada Undang-Undang tersendiri, yakni Undang-Undang Nomor 28 Tahun 2014 Tentang Hak Cipta. Sesuai Bab 1 pasal 1 butir 1 UU 28/2014, “Hak Cipta adalah hak eksklusif pencipta yang timbul secara otomatis berdasarkan prinsip deklaratif setelah suatu ciptaan

${ }^{4}$ Francis Edward Jackson Valpy, Etymological Dictionary of the Latin Language (Boston: Adamant Media Corporation, 2005), hal. 345. 
diwujudkan dalam bentuk nyata tanpa mengurangi pembatasan sesuai dengan ketentuan peraturan perundangundangan." Namun, apakah pengertian hak cipta sebatas itu saja untuk bisa mengklaim bahwa lagu Susu Murni Nasional dilindungi oleh hak cipta? Tentunya tidak, di Indonesia, peraihan hak cipta dibagi menjadi dua, yaitu dengan cara: (1) sistem deklaratif dan (2) sistem konstitutif. Sistem deklaratif adalah pernyataan bahwa suatu karya memiliki hak cipta melalui penerbitan dari sang pencipta ke muka umum, sedangkan sistem konstitutif adalah pernyataan hak cipta atas karya melalui pendaftaran karyanya ke departemen hak kekayaan intelektual. Berdasarkan riset, tidak terdapat jejak bahwa lagu Susu Murni Nasional di daftarkan ke sebuah departemen hak kekayaan intelektual. Berarti, lagu susu murni nasional meraih hak ciptanya melalui sistem deklaratif, dengan cara mempublikasikan lagunya ke muka umum.

Namun, berdasarkan Bab 2 pasal 4 UU 28/2014, hak cipta terdiri dari hak ekonomi dan hak moral. Hak ekonomi adalah suatu hak yang memberi izin kepada suatu pihak untuk mendapatkan keuntungan moneter melalui suatu karya atau ciptaan, ${ }^{5}$ sedangkan kalau hak moral itulah hak yang melekat secara abadi, ${ }^{6}$ seperti nama pencipta terhadap ciptaannya. Contoh dari ini adalah lagu Neng Neng Nong Neng, lagu tersebut menjadi sumber pendapatan uang oleh Achmad Dhani (yang memiliki hak ekonomi), sedangkan lagu tersebut bukanlah karyanya, melainkan itu karya yang ia beli melalui perjanjian dengan pengarang aslinya (hak moral). Maka dari pengertian ini, lagu Susu Murni Nasional hanya boleh dipergunakan sebagai sumber pendapatan uang Firgiawan dan Young Lex hanya kalau hak ekonomi dari Susu Murni Nasional diberi kepada mereka.

${ }^{5}$ Pasal 4, UU 28/2014.

${ }^{6}$ Pasal 5, UU 28/2014. 
Tetapi, berdasarkan UU 28/2014 hanya ada beberapa ciptaan yang diartikulasikan sebagai ciptaan yang dilindungi oleh hak cipta, yang mana salah satunya adalah lagu dan/atau musik dengan atau tanpa teks. ${ }^{7}$ Maka dari itulah, lagu ciptaan Susu Murni Nasional tergolong sebagai musik tanpa teks.

Dengan pengetahuan yang sudah diuraikan, maka di mata hukum lagu Susu Murni Nasional dilindungi oleh hak cipta yang hanya boleh diuntungkan secara moneter dari pihak Susu Murni Nasional.

\section{Elemen Musik}

Maupun pengetahuan hukum memberi kesimpulan bahwa lagu Susu Murni Nasional memiliki hak cipta serta hak-hak yang ditimbulkannya, namun apakah benar kalau tindakan Firgiawan dan Young Lex berupa sebuah tindakan plagiarisme. Untuk bisa menyimpulkan tersebut, perundang-undangan tidak memberi penjelasan seberapa jauh lagu itu boleh "mirip" dengan lagu lain, maka para mahasiswa tidak boleh hanya memandang dengan kacamata legalitas tindakan, namun harus juga menganalisa lagu ciptaan Young Lex dan Firgiawan jauh lebih dalam lagi. Untuk bisa menyimpulkan tindakannya Firgiawan dan Young Lex melalui analisa musik, maka harus dimengerti lebih dahulu elemen dari musik. Elemen musik terdiri dari:

a. Rhythm: (beat, meter, tempo, syncopation)

b. Dynamics: (forte, piano, [etc.], crescendo, decrescendo)

c. Melody: (pitch, theme, conjunct, disjunct)

d. Harmony: (chord, progression, consonance, dissonance, key, tonality, atonality) Tone color: (register, range, instrumentation)

7 Pasal 40 Ayat (1) paragraf d, UU 28/2014. 